\title{
Approaching chronic cough
}

Vijo $\underline{\text { Poulose }}^{1}$, FCCP, ABIM, Pei Yee $\underline{\text { Tiew }}^{1}$, MRCP, MMed, Choon How $\underline{H o w}^{2}$, MMed, FCFP

Wendy, a successful executive in her early 30s, visited your clinic for a review. She complained that her prolonged cough was irritating her, particularly at work. She described a dry cough with occasional whitish phlegm and a slight itch in the throat, which was especially prevalent when she had to do a long presentation.

\section{WHAT IS CHRONIC COUGH?}

In common practice, any non-acute cough ( $\geq 3$ weeks' duration) is considered 'chronic'. However, international guidelines subdivide non-acute cough into subacute (3-8 weeks duration) and chronic (> 8 weeks duration). ${ }^{(1)}$ Studies have suggested that only a small proportion of those affected by chronic cough present themselves for medical attention, ${ }^{(2)}$ and those who attend consultations may report experiencing significant distress or a reduced quality of life as a result of their cough. ${ }^{(3)}$ However, for the purpose of this article, we will focus on the common presentations and use the term 'chronic' for any prolonged cough lasting $\geq 3$ weeks.

\section{HOW COMMON IS THIS IN MY PRACTICE?}

According to the Ministry of Health Primary Care Survey 2010, cough (of varying durations) is the most common presentation, appearing in up to $25 \%$ of all general practitioner and polyclinic attendances. ${ }^{(4)}$ Chronic cough is one of the most common indications for referral to a pulmonary specialist. However, careful history-taking and physical examination at the primary care level can narrow the diagnosis in many of these patients. Chronic cough is rarely life-threatening, but serious complications like pneumothorax, syncope and cardiac arrhythmias can sometimes occur.

\section{WHAT CAN I DO IN MY PRACTICE?}

The article mainly focuses on (a) adult patients; (b) who present with cough as the primary symptom; (c) when the cough is not associated with fever, dyspnoea, weight loss or any other warning symptoms; and (d) who have a normal chest radiograph. In this group, common causes are postinfectious cough, cough variant asthma (CVA), postnasal drip syndrome (PNDS), gastro-oesophageal reflux disease (GERD), smoker's cough, use of angiotensin-converting enzyme inhibitors (ACEI) and nonasthmatic eosinophilic bronchitis (NAEB).

\section{What are some typical features of these differentials? Postinfectious cough}

This cough usually follows a viral upper respiratory tract infection and spontaneously subsides within eight weeks (subacute cough). The aetiology is believed to be transient laryngeal hyperresponsiveness.

Mycoplasma and pertussis have both been associated with postinfectious cough in adults. Mycoplasma cough usually lasts for 1-2 months and may be associated with high serum Mycoplasma titres. There is no evidence that antibiotics have any benefits in treating this cough. Pertussis, which is also known as 100-day cough or whooping cough, is increasingly seen in adults (including those who were immunised in childhood) and may last up to four months. As these patients do not usually display the typical features of pertussis, a prolonged cough may be the only main symptom. In most patients, the cough does not have a 'whooping' quality. While macrolides or doxycycline may reduce the risk of transmission, they probably have little effect on the cough itself.

\section{Cough variant asthma}

CVA is asthma presenting mostly as cough, with little or no dyspnoea. The cough may be 'wheezy' in nature. These patients sometimes present with normal spirometry and a methacholine challenge test (MCT) may be needed for diagnosis. A negative MCT essentially rules out CVA. Once confirmed, patients with CVA respond well to standard asthma therapy, such as inhaled corticosteroids.

\section{Postnasal drip syndrome}

PNDS is now referred to as upper airway cough syndrome and is caused by chronic rhinitis (allergic and nonallergic) or chronic sinusitis. Patients usually present with a runny or blocked nose, nasal dripping, and an itchy throat. Purulent discharge and facial pain may suggest concomitant sinusitis. A careful physical examination of the posterior oropharyngeal space may reveal a cobblestone appearance. Allergic rhinitis will usually respond to antihistamine treatment and a course of at least two weeks of nasal steroids. However, longer-term treatment may be required for the control of persistent allergic rhinitis, which is commonly found in Singapore. If the cough does not resolve and chronic sinusitis is suggested, the patient should be referred to an ear, nose and throat physician for further investigations and management. 


\section{Gastro-oesophageal reflux disease}

Patients experiencing this may present with classical symptoms such as acid brash, heartburn and bloating. A therapeutic trial with acid-suppressive medication, such as proton pump inhibitors, with or without promotility agents may be started. However, some patients have atypical presentations that may be due to non-acid reflux. These patients may need more specialised investigations, including upper gastrointestinal endoscopy, 24-hour pH monitoring or gastric impedance testing.

\section{Smoker's cough}

Heavy smokers can develop chronic bronchitis, generally after 40 years of age. This is classically a 'wet' cough with white, tenacious sputum and tends to occur in the morning.

\section{Cough following use of angiotensin-converting enzyme inhibitors}

Following the start of ACEI therapy, cough may be seen in up to one-third of these patients. This cough may appear immediately or as late as a few months into the therapy. Resolution of the cough usually occurs 2-4 weeks after cessation of the offending drug, although some cases may take a few months to resolve. A study from Tampines Polyclinic revealed a 30\% incidence of post-ACEI cough; the majority of the affected patients were successfully switched to angiotensin receptor blockers. ${ }^{(5)}$

\section{Nonasthmatic eosinophilic bronchitis}

NAEB is identified in patients as eosinophilic inflammation of the airway without bronchospasms and is often associated with sputum eosinophilia. Lung function tests such as spirometry and MCT return normal results. Patients respond well to inhaled corticosteroids. ${ }^{(6,7)}$

\section{How can I approach chronic cough?}

Unpublished local data on 200 consecutive cases of chronic cough assessed by Poulose et al showed that the most common causes referred to a respiratory clinic at Changi General Hospital, Singapore, were PNDS, postinfectious cough, GERD and CVA. A diagnosis could not be reached in 21 (11\%) patients. These cases included 12 patients who were lost to follow-up after the first visit. In $20 \%$ of cases, more than one aetiology was identified.

When approaching a case of chronic cough, proper historytaking is of paramount importance. Many of the referred cases in our local data were diagnosed at the first visit through the patients' detailed history alone (including four cases of smoker's cough). Other cases may present with no diagnostic clues, even after a detailed history-taking, physical examination and chest radiography. A study conducted in Singapore by Poulose et al ${ }^{(8)}$ on such cases showed that in $65 \%$ of them, a diagnosis was eventually reached. The most common aetiologies were GERD and PNDS. ${ }^{(8)}$ A suggested approach to chronic cough is given in Fig. 1, excluding cases where immediate chest radiography was warranted.

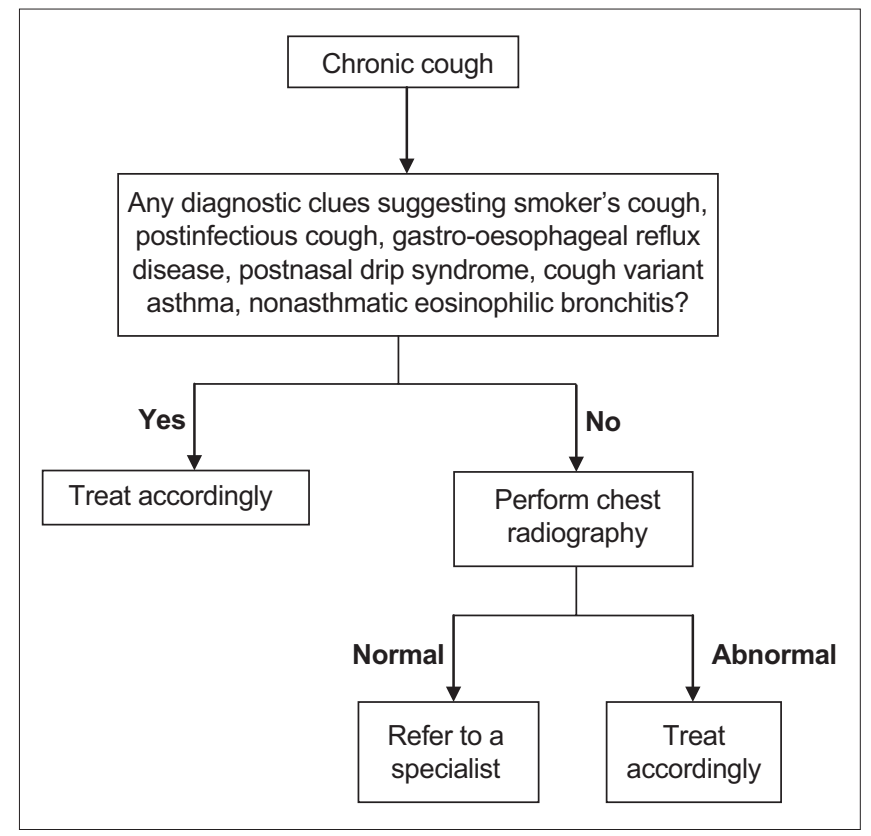

Fig. 1 Flowchart shows suggested approach to chronic cough.

\section{WHEN SHOULD I REFER TO A SPECIALIST?}

In healthcare settings in which there is no easy access to specialist care, the primary care physician may order further investigations when there are no clear diagnostic clues. An alternative approach is to try empiric treatment (a therapeutic trial) for the most common causes of chronic cough (i.e. GERD, PNDS and CVA). However, the treatment period of such empiric trials may last up to a few months and the uncertainty of success may cause patients further anxiety.

In the local context, where the specialist referral system is more efficient, we recommend referring the patient (Fig. 1). The specialist can then organise a workup, which may include a lung function test, and other endoscopic or imaging modalities. A timely negative workup may allow asymptomatic patients with chronic cough to avoid long therapeutic trials with inhaled corticosteroids or oral proton pump inhibitor therapy. ${ }^{(9)}$

After a careful history-taking, you found out that Wendy started out with an upper respiratory tract infection with rhinorrhoea and sore throat. These resolved in the first few days after presentation and only the dry cough persisted. Her physical examination was normal. You explained to Wendy that her cough was a common presentation after an infection of the upper airway, as its natural course is 4-8 weeks, and prescribed her another course of cough syrup. You received a 'Thank you' card from Wendy about two weeks later, informing you that her cough had completely resolved. 


\section{TAKE HOME MESSAGES}

1. The most common causes of chronic cough, in the local context, appear to be PNDS, postinfectious cough, GERD and CVA.

2. Postinfectious cough usually follows a viral upper respiratory tract infection and may last up to eight weeks.

3. A careful history-taking and physical examination can provide a diagnosis in many patients.

ABSTRACT Chronic cough is one of the most common reasons for referral to a respiratory physician. Although fatal complications are rare, it may cause considerable distress in the patient's daily life. Western and local data shows that in patients with a normal chest radiograph, the most common causes are postnasal drip syndrome, postinfectious cough, gastro-oesophageal reflux disease and cough variant asthma. Less common causes are the use of angiotensin-converting enzyme inhibitors, smoker's cough and nonasthmatic eosinophilic bronchitis. A detailed history-taking and physical examination will provide a diagnosis in most patients, even at the primary care level. Some cases may need further investigations or specialist referral for diagnosis.

Keywords: chronic cough, subacute cough

\section{REFERENCES}

1. Irwin RS, Madison JM. The diagnosis and treatment of cough. N Engl J Med 2000; 343: 1715-21.

2. Chung KF, Pavord ID. Prevalence, pathogenesis, and causes of chronic cough. Lancet 2008; 371: 1364-74.

3. French CL, Irwin RS, Curley FJ, Krikorian CJ. Impact of chronic cough on quality of life. Arch Intern Med 1998; 158:1657-61.

4. Ministry of Health, Singapore. Primary Care Survey 2010 - Profile of Primary Care Patients [online]. Available at: https://www.moh.gov.sg/ content/moh_web/home/Publications/information_papers/2011/primary_ care_survey2010profileofprimarycarepatients.html. Accessed January 27, 2016.

5. Ng LP, Goh PS. Incidence of discontinuation of angiotensin-converting enzyme inhibitors due to cough, in a primary healthcare centre in Singapore. Singapore Med J 2014; 55:146-9.

6. Rytilä P, Ghaly L, Varghese S, et al; Airway Inflammation Study Group. Treatment with inhaled steroids in patients with symptoms suggestive of asthma but with normal lung function. Eur Respir J 2008; 32:989-96.

7. Ribeiro M, Pereira CA, Nery LE, Beppu OS, Silva CO. High-dose inhaled beclomethasone treatment in patients with chronic cough: a randomized placebo-controlled study. Ann Allergy Asthma Immunol 2007; 99:61-8.

8. Poulose V, Bin Mohd I. Prolonged cough presenting with diagnostic difficulty: a study of aetiological and clinical outcomes. Singapore Med J $2011 ; 52: 267-70$.

9. Gibson P, Wang G, McGarvey L, et al. Treatment of Unexplained Chronic Cough: CHEST Guideline and Expert Panel Report. Chest 2015 Oct 1. chest.15-1496. [Epub ahead of print].

\section{RECOMMENDED READING}

- Chang AB, Glomb WB. Guidelines for evaluating chronic cough in pediatrics: ACCP evidence-based clinical practice guidelines. Chest 2006; 129(1 Suppl):260S-283S 


\section{SINGAPORE MEDICAL COUNCIL CATEGORY 3B CME PROGRAMME} (Code SMJ 201602A)

1. Common causes of chronic cough with a normal chest radiograph in the local setting include postnasal drip syndrome (PNDS), postinfectious cough, gastro-oesophageal reflux disease (GERD) and cough variant asthma (CVA).

2. The absence of wheezing and dyspnoea rules out CVA.

3. Spirometry may be normal in CVA.

4. A negative methacholine challenge test almost always rules out CVA.

5. GERD cannot be the cause of cough in the absence of classical symptoms such as acid brash or heartburn.

6. 24-hour $\mathrm{pH}$ monitoring is always required to diagnose GERD-induced cough.

7. Angiotensin-converting enzyme inhibitor (ACEI)-induced cough can last up to a few months after stopping medication.

8. The onset of ACEl-induced cough ranges from instantaneous to a few months after the initiation of ACEI.

9. The posterior pharynx has a cobblestone appearance in postinfectious cough.

10. Nonasthmatic eosinophilic bronchitis (NAEB) is associated with a positive methacholine challenge test.

11. Postinfectious cough usually subsides within eight weeks.

12. Postinfectious cough is believed to be the result of transient laryngeal hyperresponsiveness.

13. A thorough history-taking and physical examination can often provide a diagnosis for chronic cough.

14. In the absence of any specific diagnostic clues, experts suggest that empiric treatment with nasal steroids and antihistamines can be started for PNDS, GERD or CVA.

15. The treatment for CVA is the same as that for classical asthma.

16. Chronic cough due to Mycoplasma or pertussis responds well to macrolide therapy.

17. Inhaled corticosteroids can be used to treat both NAEB and CVA.

18. Chronic cough cannot cause serious cardiovascular complications.

19. PNDS is now referred to as upper airway cough syndrome.

20. GERD is always caused by acid reflux.

\footnotetext{
Doctor's particulars:

Name in full

MCR number

Specialty:

Email address

\section{SUBMISSION INSTRUCTIONS:}

(1) Log on at the SMJ website: http://www.sma.org.sg/publications/smjcurrentissue.aspx and select the appropriate set of questions. (2) Provide your name, email address and MCR number. (3) Select your answers and click "Submit".

RESULTS:

(1) Answers will be published in the SMJ April 2016 issue. (2) The MCR numbers of successful candidates will be posted online at the SMJ website by 4 April 2016. (3) Passing mark is $60 \%$. No mark will be deducted for incorrect answers. (4) The SMJ editorial office will submit the list of successful candidates to the Singapore Medical Council. (5) One CME point is awarded for successful candidates.

Deadline for submission: (February 2016 SMJ 3B CME programme): 12 noon, 28 March 2016.
} 